\title{
Erratum to: Trends in epidemiology and patho-anatomical pattern of proximal humeral fractures
}

\author{
Christian Bahrs • Tanja Stojicevic • \\ Gunnar Blumenstock • Stig Brorson • Andreas Badke • \\ Ulrich Stöckle • Bernd Rolauffs • Thomas Freude
}

Published online: 20 June 2014

(C) SICOT aisbl 2014

\section{Erratum to: International Orthopaedics (SICOT)}

DOI 10.1007/s00264-014-2362-6

Due to an oversight in typesetting, the authors' given names and surnames were transposed. Their names are presented correctly here.

The publisher apologizes for the inconvenience caused.

The online version of the original article can be found at http://dx.doi.org/ 10.1007/s00264-014-2362-6.

C. Bahrs $(\bowtie) \cdot$ T. Stojicevic $\cdot$ A. Badke $\cdot$ U. Stöckle $\cdot$ B. Rolauffs

T. Freude

Clinic for Traumatology and Reconstructive Surgery,

Berufsgenossenschaftliche Unfallklinik Tübingen, Eberhard Karls

University Tübingen, Schnarrenbergstr, 95, 72074 Tübingen,

Germany

e-mail: C.Bahrs@gmx.de

T. Stojicevic

e-mail: tanja.stojicevic@hotmail.de

A. Badke

e-mail: abadke@bgu-tuebingen.de

U. Stöckle

e-mail: ustoeckle@bgu-tuebingen.de

B. Rolauffs

e-mail: brolauffs@bgu-tuebingen.de

T. Freude

e-mail: tfreude@bgu-tuebingen.de

G. Blumenstock

Department of Clinical Epidemiology and Applied Biometry,

Eberhard Karls University Tübingen, Silcherstraße 5,

72076 Tübingen, Germany

e-mail: Gunnar.Blumenstock@med.uni-tuebingen.de

\section{S. Brorson}

Department of Orthopaedic Surgery, Herlev University Hospital, Herlev Ringvej 75, 2730 Herlev, Denmark

e-mail: sbrorson@hotmail.com 